\title{
A pre-intervention study of malaria vector abundance in Rio Muni, Equatorial Guinea: Their role in malaria transmission and the incidence of insecticide resistance alleles
}

\author{
Frances C Ridl*1, Chris Bass ${ }^{2}$, Miguel Torrez ${ }^{3}$, Dayanandan Govender ${ }^{1}$, \\ Varsha Ramdeen ${ }^{1}$, Lee Yellot ${ }^{3}$, Amado Edjang Edu ${ }^{4}$, Christopher Schwabe ${ }^{5}$, \\ Peter Mohloai ${ }^{6}$, Rajendra Maharaj ${ }^{1}$ and Immo Kleinschmidt ${ }^{7}$
}

\begin{abstract}
Address: ${ }^{1}$ Malaria Research Lead Programme, Medical Research Council, 491 Ridge Road, Durban, South Africa, ${ }^{2}$ Department of Biological Chemistry, Rothamsted Research, Harpenden, AL5 2JQ, UK, ${ }^{3}$ Equatorial Guinea Malaria Control Initiative, Apdo \# 606, Bata, Equatorial Guinea, ${ }^{4}$ C/O.U.A., Zona Sanitaria s/n, Bata-Litoral, Equatorial Guinea, ${ }^{5}$ Medical Care Development International, 8401 Colesville Rd, Silver Spring, Maryland, 20910, USA, ${ }^{6}$ One World Development Group International, Punta Europa, Carretera Aeropuerto, Malabo, Bioco Norte, Equatorial Guinea and ${ }^{7}$ London School of Hygiene and Tropical Medicine, Keppel St, London, WC1E 7HT, UK

Email: Frances C Ridl* - fridl@mrc.ac.za; Chris Bass - chris.bass@bbsrc.ac.uk; Miguel Torrez - mtorrez@gmail.com; Dayanandan Govender - dgovender@mrc.ac.za; Varsha Ramdeen - vramdeen@mrc.ac.za; Lee Yellot - lyellot@mcd.org; Amado Edjang Edu - edjang_1@hotmail.com; Christopher Schwabe - cschwabe@mcd.org; Peter Mohloai - mohloaip@hotmail.com; Rajendra Maharaj - rmaharaj@mrc.ac.za; Immo Kleinschmidt - Immo.Kleinschmidt@lshtm.ac.uk

* Corresponding author
\end{abstract}

Published: 29 September 2008

Malaria Journal 2008, 7:194 doi:10.1186/1475-2875-7-194
Received: 24 June 2008

Accepted: 29 September 2008

This article is available from: http://www.malariajournal.com/content/7///194

(C) 2008 Ridl et al; licensee BioMed Central Ltd.

This is an Open Access article distributed under the terms of the Creative Commons Attribution License (http://creativecommons.org/licenses/by/2.0), which permits unrestricted use, distribution, and reproduction in any medium, provided the original work is properly cited.

\begin{abstract}
Background: Following the success of the malaria control intervention on the island of Bioko, malaria control by the use of indoor residual spraying (IRS) and long-lasting insecticide-treated nets (LLITN) was extended to Rio Muni, on the mainland part of Equatorial Guinea. This manuscript reports on the malaria vectors present and the incidence of insecticide resistant alleles prior to the onset of the programme.

Methods: Anopheles mosquitoes were captured daily using window traps at $\mathbf{3 0}$ sentinel sites in Rio Muni, from December 2006 to July 2007. The mosquitoes were identified to species and their sporozoite rates, knockdown resistance $(k d r)$ and acetylcholinesterase (AChE) sensitivity measured, to define the role of vector species in malaria transmission and their potential susceptibility to insecticides.

Results: A total of 6,162 Anopheles mosquitoes were collected of which 4,808 were morphologically identified as Anopheles gambiae s.l., 120 Anopheles funestus, 1,069 Anopheles moucheti, and 165 Anopheles nili s.l. Both M and S molecular forms of Anopheles gambiae s.s. and Anopheles melas were identified. Anopheles ovengensis and Anopheles carnevalei were the only two members of the An. nili group to be identified. Using the species-specific sporozoite rates and the average number of mosquitoes per night, the number of infective mosquitoes per trap per 100 nights for each species complex was calculated as a measure of transmission risk. Both $k d r-w$ and kdr-e alleles were present in the S-form of An. gambiae s.s. (59\% and 19\% respectively) and at much lower frequencies in the M-form ( $9.7 \%$ and $1.8 \%$ respectively). The $k d r-w$ and $k d r-e$ alleles cooccurred in 103 S-form and I M-form specimens. No insensitive AChE was detected.
\end{abstract}




\begin{abstract}
Conclusion: Anopheles gambiae s.s, a member of the Anopheles gambiae complex was shown to be the major vector in Rio Muni with the other three groups playing a relatively minor role in transmission. The demonstration of a high frequency of $k d r$ alleles in mosquito populations before the onset of a malaria control programme shows that continuous entomological surveillance including resistance monitoring will be of critical importance to ensure the chosen insecticide remains effective.
\end{abstract}

\section{Background}

Malaria is a major endemic disease in Rio Muni, the mainland part of Equatorial Guinea situated at $1.512^{\circ} \mathrm{N}$ $10.267^{\circ}$ on the west coast of Central Africa. Estimates from a Plasmodium falciparum prevalence survey conducted in 2007 among children between two and 15 years of age showed site-specific parasitaemias to vary from $54 \%$ to $89 \%$ with an average of $72 \%$ (unpublished data I. Kleinschmidt and L. Benavente). Following the success of the Bioko Island Malaria Control Project (BIMCP) [1,2] malaria control has been extended to Rio Muni under the Equatorial Guinea Malaria Control Initiative (EGMCI) by a staged roll-out of indoor residual house spraying (IRS) in Litoral and Kie-Ntem provinces and long-lasting insecticide-treated net (LLITN) distribution in the other two provinces (Cento Sur and Wele Nzas). Extensive information and education campaigns are being conducted and all areas will benefit from the introduction of free artemisinin-based combination therapy starting in July 2008. This initiative, to substantially reduce malaria on the mainland using IRS and LLITNs is being funded by the Global Fund to fight Aids, Tuberculosis and Malaria (GFATM) and Marathon Oil Company and is run in partnership with the government of Equatorial Guinea, Medical Care Development International (MCDI), One World Development Group International (OWDGI), Medical Research Council of South Africa (MRC), Harvard and Yale Universities and the London School of Hygiene and Tropical Medicine.

The tropical all year round humid climate and the many rivers and streams, both fast and slow flowing, provide ideal breeding conditions for different malaria vectors. Earlier studies have shown Anopheles gambiae sensu lato (s.l.) and Anopheles funestus to be the major vectors of malaria on the mainland of Equatorial Guinea [3-5]. This paper reports on the composition, density, infectivity, knockdown resistance $(k d r)$ and insensitive acetylcholinesterase (iAChE) status of malaria vector species exiting houses through window traps before the start of the intervention.

\section{Materials and methods \\ Entomological monitoring}

In November 2006, window traps were installed at six houses at each of 30 sentinel sites selected in each of the four provinces (Figure 1); eleven sites in the coastal province, Litoral, which includes Bata, the principle city on the mainland, five sites in Centro Sur which comprises the centre of the mainland, six sites in Kie Ntem in the northeast and eight sites in Welas Nzas in the south-east. The extensive distribution of the sentinel sites throughout the country facilitated localized monitoring of malaria vectors. These data are useful for evaluating the effectiveness of IRS and LLITNs and for long term planning regarding choice of appropriate insecticide.

Mosquito collections from window traps were described previously by Sharp et al [2]. Briefly, the contents of window traps were emptied daily by the home owner into pre-labelled specimen jars containing isopropanol. Night control sheets specifying the nights worked were documented and both jars and sheets were collected and replaced at four week intervals. Mosquitoes were collected during an eight month period, from December 2006 to July 2007, before the start of the first spray round to establish a baseline for comparison between pre- and postintervention periods.

\section{Identification of vector species, molecular forms, kdr and AChE mutations}

Mosquitoes were separated into Culicinae and Anophelinae and counted. Anophelines were morphologically identified into An. gambiae s.l., An. funestus, Anopheles moucheti and Anopheles nili s.l., using the keys described by Gillies and De Meillon [6], Gillies and Coetzee [7] and Hervy et al [8] and, subsequently, stored in isopropanol.

DNA was extracted from the head and thorax [9] of a subsample of mosquitoes to determine family member species using Polymerase Chain Reaction (PCR). The protocols of Scott et al [10], Koekemoer et al [11], Kengne et al $[12,13]$ were used to identify family members of An. gambiae s.l., An. funestus, An. nili s.l. and An. moucheti respectively and the molecular forms of An.gambiae sensu stricto (s.s.) were determined according to the method described by Fanello et al [14]. The presence of the west-African LeuPhe and east-African Leu-Ser $k d r$ mutations was determined in 505 An. gambiae s.s individuals using the TaqMan PCR protocol described by Bass et al [15]. A new TaqMan assay devised by Bass et al [16] was used to determine Plasmodium falciparum sporozoite rates. Insensitive 


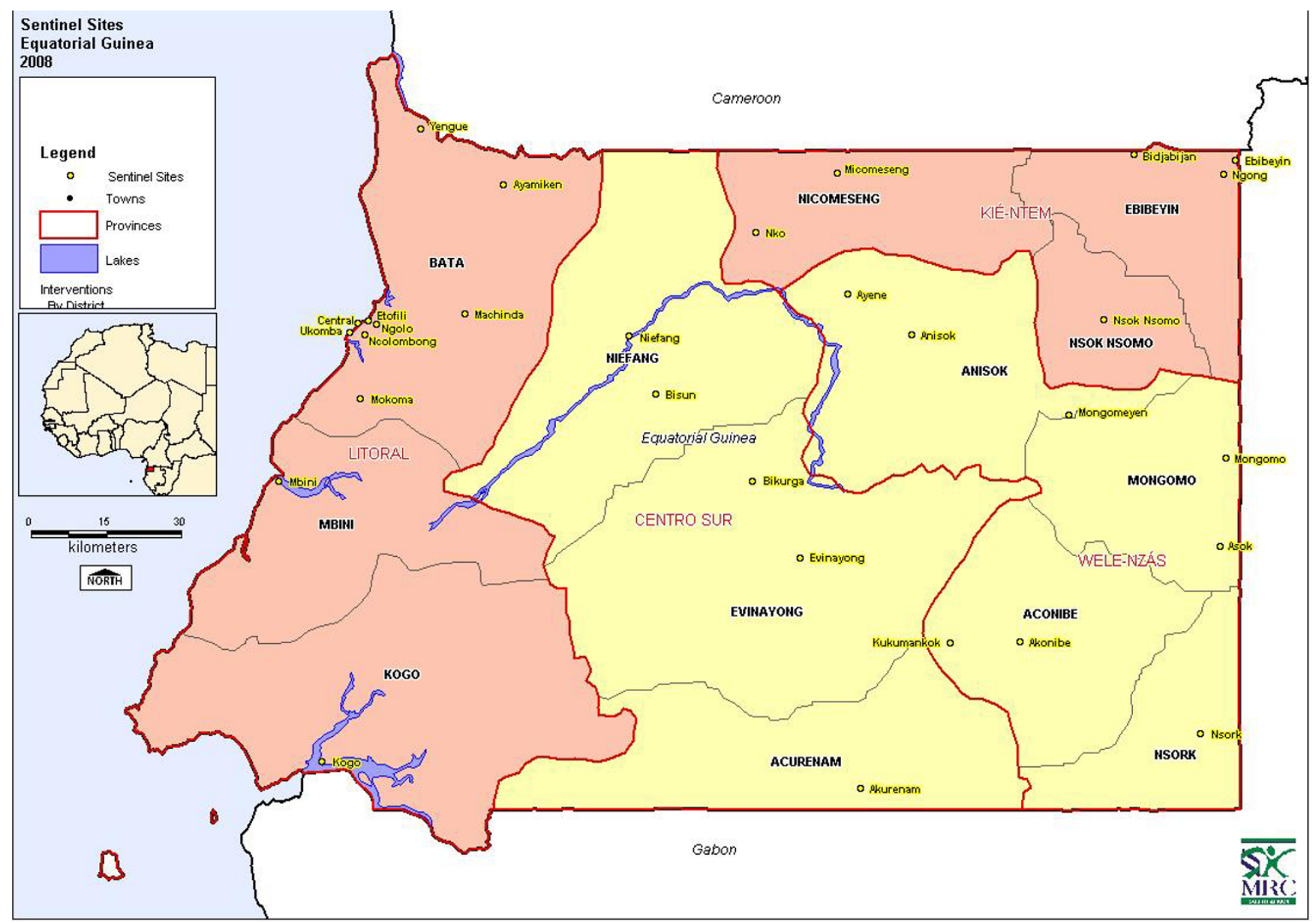

Figure I

Map of the sentinel sites in the four provinces of Rio Muni, Equatorial Guinea.

AChE was determined using the PCR method described by Weil et al [17].

\section{Transmission risk}

The number of infective mosquitoes per trap per 100 nights for each species complex was calculated as a measure of transmission risk.

\section{Sequence analysis of $\mathbf{k d r}$}

The results of $k d r$ genotyping using the TaqMan assay were verified by sequencing the relevant region of the sodium channel gene in 50 of the 505 samples analysed. This was carried out using two primers (MosF1, 5'-GATAATGTGGATAGATTCCCCG-3 and MosR1, 5'-CGTTGGTGCAGACAAGGATG-3') flanking the mutation site. PCR reactions $(25 \mu \mathrm{l})$ contained $1 \mu \mathrm{l}$ of genomic DNA, $12.5 \mu \mathrm{l}$ of $2 \times$ PCR master mix (Promega) and $100 \mathrm{ng}$ of each primer. PCR products were ethanol precipitated and direct sequenced using an internal primer (MosSeq1 5'-CCATGATCTGCCAAGATGGA-3') and the ABI BigDye Termina- tor Cycle Sequencing kit followed by analysis on a 310 Automated DNA Sequencer (PE Applied Biosystems).

\section{Statistical analysis}

The genotypic frequencies at the kdr locus were compared to Hardy-Weinberg expectations using the exact test procedures implemented in GenePOP (ver.3.4) software [18].

\section{Results}

\section{Mosquito collections and molecular identification}

A total of 6,162 Anopheles mosquitoes were collected of which 4,808 (78\%) were morphologically identified as An. gambiae s.l., 120 (2\%) An. funestus, 1,069 (17\%) An. moucheti and 165 (3\%) An. nili s.l. (Table 1). The four identified family groups were found sympatrically in all four provinces. Large variations in mosquito numbers and mosquito species composition existed between sentinel sites and also between different months. 
Table I: Total number of anophelines caught per province December 2006-July 2007

\begin{tabular}{lcccc}
\hline Province & An. gambiae s.l. & An. funestus & An. moucheti & An. nili s.l. \\
\hline Centro Sur & 225 & 3 & 382 & 26 \\
Litoral & 3262 & 76 & 36 & 113 \\
Wele Nzas & 580 & 29 & 153 & 23 \\
Kie-Ntem & 741 & 12 & 498 & 3 \\
\hline Total & 4808 & 120 & 1069 & 165 \\
\hline
\end{tabular}

Anopheles gambiae s.s. and Anopheles melas were the only two members of the An. gambiae complex to be identified $(\mathrm{n}=930)$. An. gambiae s.s was identified from 29 of the 30 sentinel sites and accounted for 776 of the An. gambiae s.l. identifications. An. melas was predominantly identified from the two coastal port cities of Cogo and Mbini where they made up $88 \%(n=112)$ and $79 \%(n=67)$ respectively of the total An. gambiae s.l. identified at these two sites. Two specimens were also collected from Yengue, a town in the north-west of Rio Muni, bordering on Cameroon. The S-molecular form of An. gambiae s.s. was found in all four provinces and the M-form, only in Litoral, where it accounted for $44 \%$ of identifications $(n=350)$. The two forms were found sympatrically and no hybrids were identified.

Anopheles moucheti was the second most abundant vector accounting for $17 \%$ of the total and was identified from 22 sites. It was the only member of the An. moucheti group to be identified. An. funestus was collected from fourteen sentinel sites and was the only member of the An. funestus group to be identified and accounted for $2 \%$ of the total number of Anopheline mosquitoes caught.

Anopheles nili s.l. accounted for 3\% of the total Anopheles population and was found at seven sentinel sites: Ayamiken, Ayene, Machinda, Ngong, Niefang, Nkue and Yengue. Of the 151 An. nili s.l. tested, 98 and 53 were identified as Anopheles ovengensis and Anopheles carnevalei respectively. Anopheles carnevalei was only identified from Yengue where it accounted for $50 \%$ of the total An. nili s.l. identified.

\section{Plasmodium falciparum sporozoite and transmission rates}

Sporozoite rates were $4.1 \%(\mathrm{n}=49)$ for An. funestus, $4.1 \%$ $(\mathrm{n}=74)$ for An. ovengensis, 3.3\% ( $\mathrm{n}=603)$ for An. gambiae s.s. and $1.6 \%(\mathrm{n}=126)$ for $A n$. moucheti. The sporozoite rate for An. melas was $4.4 \%(\mathrm{n}=137)$. Anopheles carnevalei was not shown to be involved in transmission although numbers tested were low $(\mathrm{n}=52)$. The estimated number of An. gambiae s.l., An. moucheti, An. nili s.l. and An. funestus per window trap per 100 nights was $15.5,3.4,0.5$ and
0.4 respectively. Using the species complex sporozoite prevalence (3.5\%, $1.6 \% 2.6 \%$ and $4.1 \%$ respectively) the number of infective mosquitoes per trap per 100 nights for each species was $0.5,0.06,0.01$ and 0.02 respectively.

\section{Kdr allele frequencies in $M$ and $S$ molecular forms of An. gambiae s.s}

$393 \mathrm{~S}$ and $113 \mathrm{M}$ molecular forms of An. gambiae s.s. were analysed for the presence of $k d r-w$ and $k d r-e$ alleles using a recently described TaqMan assay (Table 2). The results using the new assay were compared with sequencing in a subset of 50 of the specimens analysed and the two methods were found to be in complete agreement. Kdr-e and $k d r-w$ resistance alleles were present in S forms with a higher frequency of the $k d r-w$ allele (59\%) than the kdr-e allele (19\%). Both alleles also occurred in the M-forms but at much lower frequencies of $9.7 \%$ for $k d r-w$ and $1.8 \%$ for $k d r-e$. Both the $k d r-w$ and $k d r-e$ alleles were present in $S$ form samples in all four provinces with frequencies of the $k d r-w$ allele of $51 \%$ in Litoral, $47 \%$ in Centro Sur, $64 \%$ in Wele Nzas and $73 \%$ in Kie Ntem and frequencies of the $k d r-e$ allele of $32 \%$ in Litoral, $24 \%$ in Centro Sur, $8 \%$ in Wele Nzas and $14 \%$ in Kie Ntem. The $k d r-w$ and $k d r-e$ alleles were found to co-occur in a single $\mathrm{M}$ form specimen and in $103 \mathrm{~S}$ form specimens (Table 2). Sample numbers were sufficient to compare $k d r$ gene frequencies with Hardy Weinberg expectations in populations collected from a number of sites. These included Bata City in Litoral, Bisun in Centro Sur, Mongomeyen in Wele Nzas and Ebebiyin in Kie-Ntem. Genotypic frequencies of both M and $S$ form populations in Bata City showed significant deviations from Hardy-Weinberg expectations with a heterozygote deficit $(\mathrm{P}<0.001)$. The same was true of the $\mathrm{S}$ form population in Bisun in this instance due to a heterozygote excess $(\mathrm{P}<0.05)$. The genotypic frequencies of the $S$ form populations at the other two localities were not significantly different from Hardy Weinberg expectations (P $=1$ for the Mongomeyen population and $\mathrm{P}=0.39$ for the Ebebiyin population).

\section{AChE resistance}

All 200 mosquitoes tested for insensitive AChE were found to be susceptible.

\section{Discussion}

Anopheles gambiae s.l. was shown to be the main vector within this geographical region with the other three species playing a relatively minor role due to their low densities. A sporozoite rate of $4.4 \%$ for An. melas indicates its involvement in malaria transmission in the two sentinel sites from which it was identified.

Previous studies in Equatorial Guinea have shown $A n$. gambiae s.l. and An. funestus to be the main vectors of malaria [3-5]. Elsewhere in West and Central Africa An. 
Table 2: Kdr genotype frequencies in An. gambiae s.s. in Rio Muni, 2006-2007

\begin{tabular}{|c|c|c|c|c|c|c|c|c|c|c|}
\hline \multirow[t]{2}{*}{ Province } & \multirow[t]{2}{*}{ District } & \multirow[t]{2}{*}{ Locality } & \multirow[t]{2}{*}{$\mathrm{n}$} & \multirow[t]{2}{*}{ molecular form } & \multicolumn{6}{|c|}{ kdr genotypes } \\
\hline & & & & & $S / S$ & $S / R w$ & $\mathrm{~S} / \mathrm{Re}$ & $\mathrm{Rw} / \mathrm{Rw}$ & $\mathrm{Re} / \mathrm{Re}$ & $\mathrm{Re} / \mathrm{Rw}$ \\
\hline \multirow[t]{17}{*}{ Litoral } & Bata & Yengue & 25 & $M$ & 20 & 4 & I & 0 & 0 & 0 \\
\hline & & & 33 & $S$ & 3 & 3 & 5 & 10 & 2 & 10 \\
\hline & & Ayamiken & 5 & S & 1 & 3 & 1 & 0 & 0 & 0 \\
\hline & & Machinda & 1 & $\mathrm{~S}$ & 0 & 1 & 0 & 0 & 0 & 0 \\
\hline & Bata City & Ngolo & 9 & $M$ & 6 & 0 & 0 & 1 & I & 1 \\
\hline & & & 29 & $\mathrm{~s}$ & 1 & 0 & 0 & 11 & 6 & 11 \\
\hline & & Etofili-Lubi & 1 & $M$ & 1 & 0 & 0 & 0 & 0 & 0 \\
\hline & & & 9 & $\mathrm{~S}$ & 0 & 0 & 0 & 6 & 1 & 2 \\
\hline & & Centro & 2 & $S$ & 0 & 0 & 0 & 0 & 0 & 2 \\
\hline & & Ukomba & 60 & $M$ & 51 & 9 & 0 & 0 & 0 & 0 \\
\hline & & & 12 & $\mathrm{~S}$ & 4 & I & 0 & 1 & I & 5 \\
\hline & & Ncolombong & 11 & $M$ & 8 & 2 & 0 & I & 0 & 0 \\
\hline & & & 19 & $\mathrm{~S}$ & 1 & 0 & 0 & 2 & 2 & 14 \\
\hline & Cogo & Mbini & 6 & $M$ & 4 & I & 0 & 0 & 0 & 0 \\
\hline & & & 5 & $S$ & 1 & 4 & 0 & 1 & 0 & 0 \\
\hline & & Cogo & 1 & $M$ & 1 & 0 & 0 & 0 & 0 & 0 \\
\hline & & & 1 & $S$ & 0 & 0 & 0 & I & 0 & 0 \\
\hline \multirow[t]{5}{*}{ Centro Sur } & Niefang & Niefang & 13 & S & 0 & 3 & 2 & 2 & 1 & 5 \\
\hline & & Bisun & 48 & $S$ & 3 & 20 & 5 & 6 & 2 & 12 \\
\hline & Evinayong & Bicurga & 5 & S & 2 & 2 & 0 & 1 & 0 & 0 \\
\hline & & Evinayong & 17 & $S$ & 2 & 3 & I & 7 & 0 & 4 \\
\hline & Akurenam & Akurenam & 5 & S & 1 & 0 & 0 & 1 & 0 & 3 \\
\hline \multirow[t]{7}{*}{ Wele Nzas } & Anisok & Ayene & 23 & S & 2 & 11 & I & 4 & 0 & 5 \\
\hline & & Anisok & 3 & S & 0 & 0 & 0 & 2 & 0 & I \\
\hline & Mongomo & Mongomeyen & 49 & $S$ & 4 & 19 & 2 & 19 & 0 & 5 \\
\hline & & Mongomo & 4 & $\mathrm{~S}$ & 0 & 0 & 0 & 4 & 0 & 0 \\
\hline & & Asok & 1 & $\mathrm{~S}$ & 0 & I & 0 & 0 & 0 & 0 \\
\hline & Nsork & Nsork & 11 & $\mathrm{~s}$ & 1 & 2 & 0 & 7 & 0 & I \\
\hline & & Aconibe & 6 & $S$ & 0 & 1 & 1 & 3 & 0 & 1 \\
\hline \multirow[t]{3}{*}{ Kie-Ntem } & Micomiseng & Nkue & 17 & $\mathrm{~S}$ & 2 & 9 & 2 & 2 & 0 & 2 \\
\hline & Ebebiyin & Ngong & 26 & $\mathrm{~S}$ & 0 & 6 & 1 & 19 & 0 & 0 \\
\hline & & Ebebiyin & 49 & $\mathrm{~S}$ & 1 & 0 & 0 & 29 & I & 18 \\
\hline
\end{tabular}

gambiae s.l., An. funestus, An. moucheti and An. nili s.l. have been shown to be effective vectors with EIR rates ranging from 1-1000 infective bites per year recorded [19]. In this study, all four identified groups from Rio Muni have been shown to be involved in transmission of malaria with $A n$. gambiae s.s. being the major vector. Although An. funestus was found to have the highest sporozoite rate, the number caught was very low hence it was not shown to be a major vector.

Anopheles nili has recently been described as a complex consisting of four member species based on morphological criteria: An. nili, Anopheles somalicus, An. carnevalei and An. ovengensis [12].Anopheles carnevalei is relatively rare in occurrence and has so far only been reported from the equatorial forests of Ivory Coast and Cameroon [20] and from a village in Equatorial Guinea, Yengue [21,22]. Anopheles ovengensis has been reported from southern Cameroon [23]. The results of this study further provide proof of the distribution of An. ovengensis to extend throughout the northern part of Equatorial Guinea as was suggested by Awono-Ambene [23] and confirms the presence of An. carnevalei in Yengue, a village in the north-west of the mainland where it was sympatric with An. ovengensis. These collections were all made from window traps thus indicating some degree of endophilic behaviour although previous studies suggest predominately exophilic habits [23].

Resistance of mosquitoes to insecticides usually arises through one of two mechanisms, or a combination of the two; metabolic resistance due to increased production of detoxifying enzymes and target site resistance due to mutations in the sodium channel, acetylcholinesterase or GABA receptor [24]. $K d r$ is a target site resistance of the sodium channel and is one of the mechanisms conferring resistance to pyrethroid and DDT insecticides. Two mutations have been described, a leucine-phenylalanine substitution originally found in west-African An. gambiae s.l. [25] and a leucine-serine substitution found in east-African An. gambiae s.l. [26]. However, recent studies in Cameroon and Gabon have shown that these mutations are 
not unique to these geographical regions and that there is considerable overlap with both being present in the same populations $[27,28]$. Both the resistance alleles were identified in the populations examined in this study. The $k d r$ $w$ and $k d r-e$ alleles were present at low frequencies in M forms $(9.7 \%$ and $1.8 \%)$ and in much higher frequencies in $S$ forms with the frequency of the $k d r-w$ allele $59 \%$ and the frequency of the $k d r-e$ allele $19 \%$. The observed gene frequencies are in close concordance with those reported recently in the neighbouring country of Cameroon where $k d r-w$ and $k d r-e$ alleles were present in $M$ form populations at frequencies of $6.3 \%$ for $k d r-w$ and $1.1 \%$ for $k d r-e$ and in $\mathrm{S}$ form populations at frequencies of 52.7 and $13.9 \%$ [29]. This correlation in observed gene frequencies could indicate that the $k d r$ alleles have migrated from Cameroon to Equatorial Guinea or vice versa. It would be interesting in future to sequence the sodium channel gene regions flanking the $k d r$ locus, in particular intron I upstream of the mutation site, as this will provide evidence as to whether the $k d r$ mutations have arisen once and spread between the two countries or represent independent mutation events. It may also reveal the extent of migration between populations in Equatorial Guinea and Cameroon. Interestingly the gene frequencies we observed on the mainland differ significantly from those seen on the island part of Equatorial Guinea, Bioko, where prior to the onset of the spray programme, $50 \%$ of the $\mathrm{M}$-forms carried the $k d r-w$ allele in either the homozygous or heterozygous form while it was completely absent in the S-form [30,2]. However, previous studies have suggested that An. gambiae populations on Bioko are to a large extent isolated from mainland populations [29].

As reported previously in the neighbouring countries of Cameroon and Gabon [28,29] we observed a large number of $\mathrm{Re} / \mathrm{Rw}$ genotypes in the localities sampled in this study (26\% of $S$ form mosquitoes carried this genotype). Indeed this was the predominant genotype seen in $\mathrm{S}$ form mosquitoes after the Rw/Rw genotype (34\%). A recent study has shown that this genotype confers a significant degree of resistance to DDT, although the level of resistance is not significantly greater than that conferred by Rw/Rw [29]. Significantly we also recorded this genotype in a single $M$ form specimen. This result was confirmed by sequencing and to our knowledge represents the first report of this genotype in $M$ form mosquitoes. Further screening for $k d r$ in $\mathrm{M}$ form populations in Equatorial Guinea will reveal the extent of this genotype in the $\mathrm{M}$ form but this initial study indicates it may be currently found at an extremely low frequency.

In the Bata City area of Litoral both $\mathrm{M}$ and $\mathrm{S}$ populations showed significant deviations from Hardy-Weinberg expectations $(\mathrm{P}<0.001)$ and this was due to a heterozy- gote deficit. As $k d r$ is a recessive trait $[25,26]$ and only homozygous genotypes express the resistance phenotype, studies need to be implemented to determine the origin of the insecticide selection pressure as is observed from the high frequency of homozygous resistant individuals in Bata City before IRS. Clearly the presence of both $k d r-e$ and $k d r-w$ alleles at high frequencies in these populations may have implications for the effectiveness of the current vector control programme which is based on pyrethroid insecticides.

AChE is the target site of organophosphates and carbamate insecticides and insensitive AChE in mosquitoes coincides with high insecticide resistance to these insecticide classes. No insensitive AChE was detected in this baseline study indicating continued efficacy of these insecticide classes. Coleman et al [31] reviewed published insecticide resistance data in Africa and found eight sites with reported carbamate resistance and 13 sights with organophosphate resistance. They attributed this to the limited application of carbamates and organophophates in large-scale vector control and the lack of resistance monitoring.

This study provides contemporary information on the distribution of malaria species and their role in malaria transmission in Rio Muni, Equatorial Guinea. It also provides useful information on measures of insecticide resistance for the vector control programme. Pyrethroids have been selected as the insecticide of choice for the first spray round due to its low toxicity in humans, its longer residual effect and for cost efficacy and procurement implications. WHO susceptibility tests in 2000 showed resistance to DDT but susceptibility to both deltamethrin and permethrin [5,32]. In bioassays conducted in 2007 with alphacypermethrin (Fendona), there was 95.5\% mortality in the exposed group by the end of the observation period (24 hrs) (personnel communication M. Torrez 2007). In West Africa, large scale agricultural pyrethroid use has resulted in very high insecticide resistance [3]. However in Equatorial Guinea pyrethroids have not been widely used as an agricultural insecticide. Therefore this studies findings of $k d r$ mutations at such high frequency in mosquito populations in Equatorial Guinea (particularly in $S$ form populations) is unexpected. Nevertheless, the presence of $k d r$ alleles at the observed frequencies could impact on the choice of insecticide for future spray rounds and will require ongoing monitoring and evaluation to ensure the chosen insecticide remains effective, a process the EGMCI has put in place. Carbamates remain a viable alternative in the absence of insensitive AChE and have been successfully used in a number of spray programmes including on the island of Bioko and in Mozambique [2,33]. Further biochemical testing is planned to determine whether or not other resistant mechanisms are present in the mos- 
quito populations and to assess if these develop as a result of selection pressure exerted by the IRS and ITN vector control operations.

\section{Competing interests}

The authors declare that they have no competing interests.

\section{Authors' contributions}

FCR co-designed the study, carried out laboratory analyses of mosquitoes, participated in data analysis and interpretation and was involved in the drafting of the manuscript. $\mathrm{CB}$ carried out $k d r$ laboratory analyses, analysed and interpreted the $k d r$ results and assisted in the drafting of the manuscript. MT carried out the susceptibility assays and contributed to the drafting of the manuscript. DG managed the database, assisted with the analysis of results and contributed to the manuscript. VR assisted with laboratory analyses and helped draft the manuscript. LY was responsible for the IRS programme, monitoring of window traps and helped draft the manuscript. AE was responsible for the window trap collections and preparation of mosquitoes for analysis and helped draft the manuscript. CS was responsible for the overall management of the control programme and assisted in drafting the manuscript. PM assisted with mosquito collections and helped draft the manuscript. RM helped draft the manuscript and critical evaluation thereof. IK co-designed and coordinated the study and was involved in the drafting of the manuscript and critical evaluation thereof. All authors read and approved the manuscript.

\section{Acknowledgements}

The authors would like to thank Drs Adel Chaouch, Brian Linder and Susan Rynard from Marathon Oil Company for their encouragement and constructive participation in the EGMCl; Dr Gloria Nseng, Director of the National Malaria Control Programme in Equatorial Guinea for her oversight and direction of the malaria control efforts in the country and $\mathrm{Mr}$ Simon Abaga, Ministry of Health and Social Welfare Entomologist, for his support of field-based activities; Jaime Kuklinski, Ruben Biebeda and Blas Abeso from One World Development Group International (OWDGI) for the collection of mosquitoes and management of vector monitoring component of the fieldwork in the EGMCl; Natashia Morris for the preparation of the map; Dr Mike Coleman for his interest and support in this project and Inbarani Naidoo for critically reading the manuscript.

\section{References}

I. Kleinschmidt I, Sharp BL, Benavente L, Schwabe C, Torrez M, Kuklinski J, Morris N, Raman J, Carter J: Reduction in infection with Plasmodium falciparum one year after the introduction of malaria control interventions on Bioko Island, Equatorial Guinea. Am J Trop Med Hyg 2006, 74:972-978.

2. Sharp BL, Ridl FC, Govender D, Kuklinski J, Kleinschmidt I: Malaria vector control by indoor residual insecticide spraying on the tropical island of Bioko, Equatorial Guinea. Malar J 2007, 6:52.

3. Molina R, Benito A, Roche J, Blanca F, Amele C, Sanchez A, Alvar J: Baseline entomological data for a pilot malaria control programme in Equatorial Guinea. J Med Entomol 1993, 3:622-624.

4. Roche J, Ayecaba S, Amela C, Alvar J, Benito A: Epidemiological characteristics of malaria in Equatorial Guinea. Res Rev Parasitol 1996, 56:99-104.
5. Molina R, Benito A, Blanca F, Roche J, Otunga B, Alvar J: The Anopheles of Equatorial Guinea. Ethology and susceptibility studies. Res Rev Parasitol 1996, 56(2-3): I05-1 I0.

6. Gillies MT, De Meillon BL: The Anophelinae of Africa south of the Sahara Publication of the South African Institute for Medical Research, Johannesburg; 1968:54.

7. Gillies MT, Coetzee M: A Supplement to the Anophelinae of Africa South of the Sahara (Afrotropical Region) Publication of the South African Institute for Medical Research, Johannesburg; 1987:55.

8. Hervy JP, Le Goff G, Geoffroy JP, Herve L, Manga L, Brunhes J: The Anopheline mosquitoes of the Afrotropical region. An identification and training software. ORSTROM edition. Serie Didactiques. Paris, France (in French, English and Portuguese) 1998.

9. Collins FH, Mendez MZ, Rasmussen MO, Mehaffey PC, Bensansky NJ, Finnerty $\mathrm{V}$ : A ribosomal RNA gene probe differentiates member species of the Anopheles gambiae complex. Am J Trop Med Hyg 1987, 37:37-4I.

10. Scott JA, Brogdon WG, Collins FH: Identification of single specimens of the Anopheles gambiae group by polymerase chain reaction. Am J Trop Med Hyg 1993, 49:520-529.

II. Koekemoer LL, Kamau L, Hunt RH, Coetzee M: A cocktail polymerase chain reaction assay to identify members of the Anopheles funestus (Diptera: Culicidae) group. Am J Trop Med Hyg 2002, 6:804-8II.

12. Kengne $P$, Awono-Ambene $P$, Antonio-Nkondjio $C$, Simard F, Fontenille D: Molecular identification of the Anopheles nili group of African malaria vectors. Med Vet Entomol 2003, 17:67-74.

13. Kengne P, Awono-Ambene P, Awono-Ambene HP, Simard F, Awolola TS, Fontenille D: Molecular differentiation of three closely related members of the mosquito species complex, Anopheles moucheti, by ribosomal DNA polymorphism. Med Vet Entomol 2007, 21:177-082.

14. Fanello C, Santolamazza F, della Torre A: Simultaneous identification of species and molecular forms of the Anopheles gambiae complex by PCR-RFLP. Med Vet Entomol 2002, 16:46I-464.

15. Bass C, Nikou D, Donnelly MJ, Williamson MS, Ranson H, Ball A, Vontas J, Field LM: Detection of knockdown resistance (kdr) mutations in Anopheles gambiae: a comparison of two new highthroughput assays with existing methods. Malar J 2007, 6: I I I.

16. Bass C, Nikou D, Blagborough AM, Williamson MS, Vontas J, Sinden RE, Field LM: PCR-based detection of Plasmodium in Anopheles mosquitoes: a comparison of a new high-throughput assay with existing methods. Malar J 2008, 7:177.

17. Weil M, Malcolm C, Chandres F, Mogensen K, Berthomieu A, Marquine $M$, Raymond $M$ : The unique mutation in ace-I giving high insecticide resistance is easily detectable in mosquito vectors. Insect Mol Biol 2004, I 3(I): I-7.

18. Raymond M, Rousset F: GENEPOP (version I.2): Population genetics software for exact tests and ecumenicism. J Heredity 1995, 86:248-249.

19. Fontenille D, Simard F: Unravelling complexities in human malaria transmission dynamics in Africa through comprehensive knowledge of vector populations. Comparative Immunology, Microbiology and Infectious Disease 2004, 27:357-375.

20. Brunhes J, Le Goff G, Geoffroy B: Afro-Tropical anopheline mosquitoes. III. Description of three new species: Anopheles carnevalei sp. Nov., An. hervyi sp. Nov., and An. dualaensis sp. Nov., and resurrection of An. rageaui Mattingly and Adam. J Am Mosq Control Assoc 1999, I 5(4):552-558.

21. Cano J, Nzambo S, Buatiche JN, Ondo-Esono M, Micha F, Benito A: Anopheles (Cellia) carnevalei in Equatorial Guinea (West Central Africa)). J Am Mosq Control Assoc 2003, 19(4):435-437.

22. Cano J, Descalzo MA, Moreno M, Chen Z, Nzambo S, Bobuakasi L, Buatiche JN, Ondo M, Micha F, Benito A: Spatial variability in the density, distribution and vectorial capacity of anopheline species in a high transmission village (Equatorial Guinea). Malar J 2006, 5:21.

23. Awono-Ambene HP, Kengne P, Simard F, Antonio-Nkondjia C, Fontenille D: Description and bionomics of Anopheles (Cellia) ovengensis (Diptera: Culicidae), a new malaria vector species of the Anopheles nili group from south Cameroon. J Med Entomol 2004, 4I(4):56I-568.

24. Hemingway J, Hawkes NJ, McCarroll L, Ranson H: The molecular basis of insecticide resistance in mosquitoes. Insect Biochem Mol Biol 2004, 34:653-665. 
25. Martinez-Torres D, Chandre F, Williamson MS, Darriet F, Berge JB, Devenshire AL, Guillet P, Pasteur N, Pauron D: Molecular characterization of pyrethoid knockdown resistance $(k d r)$ in the major malaria vector Anopheles gambiae s.s. Insect Mol Biol 1998, 7:179-184.

26. Ranson $H$, Jensen $B$, Vulule JM, Wang $X$, Hemingway J, Collins FH: Identification of a point mutation in the voltage-gated sodium channel gene of Kenyan Anopheles gambiae associated with resistance to DDT and pyrethoids. Insect Mol Biol 2000, 9(5):49|-497.

27. Etang J, Fonjo E, Chandre F, Morlais I, Brengues C, Nwane P, Chouaibou M, Ndjemai H, Simard F: Short report: First report of knockdown mutations in the malaria vector Anopheles gambiae from Cameroon. Am J Trop Med Hyg 2006, 74(5):795-797.

28. Pinto J, Lynd A, Elissa N, Donnelly MJ, Costa C, Gentile G, Caccone A, Do Rosario VE: Co-occurrence of East and West kdr mutations suggests high levels of resistance to pyrethroid insecticides in Anopheles gambiae from Libreville, Gabon. Med Vet Entomol 2006, 20:27-32.

29. Reimer L, Fonjo E, Patchoke S, Diallo B, lee $Y, N g$ A, Ndjemai HM, Atangana J, Traore SF, Lanzaro G, Cornel AJ: Relationship between kdr mutation and resistance to Pyrethoid and DDT insecticides in natural populations of An. gambiae. J Med Ento$\mathrm{mol} 2008,45(2): 260-266$.

30. Reimer L, Tripet F, Slotman M, Spielman A, Fonjo E, Lanzaro GC: An unusual distribution of the kdr gene among populations of Anopheles gambiae on the island of Bioko, Equatorial Guinea. Insect Mol Biol 2005, 14(6):683-688.

31. Coleman M, Sharp B, Seocharan I, Hemingway J: Developing an evidence based decision support system for rational insecticide choice in the control of African malaria vectors. J Med Entomol 2006, 43(4):663-668.

32. Bagayoko M, Ameneshwa B, Faye O, Lymo E, Govere J, Gebremariam $M$, Manga $L$ : The status of malaria vector resistance to insecticides used for public health in the African region. Communicable Diseases Bulletin for the African Region 3(I):5-7.

33. Sharp BL, Kleinschmidt I, Streat E, Maharaj R, Barnes KI, Durrheim DN, Ridl FC, Morris N, Seocharan I, Kunene S, La Grange JJP, Mthembu JD, Maartens F, Martin CL, Barreto A: Seven years of regional control collaboration-Mozambique, South Africa, and Swaziland. Am J Trop Med Hyg 2007, 76(I):42-47.

Publish with Bio Med Central and every scientist can read your work free of charge

"BioMed Central will be the most significant development for disseminating the results of biomedical research in our lifetime. "

Sir Paul Nurse, Cancer Research UK

Your research papers will be:

- available free of charge to the entire biomedical community

- peer reviewed and published immediately upon acceptance

- cited in PubMed and archived on PubMed Central

- yours - you keep the copyright

Submit your manuscript here:

http://www.biomedcentral.com/info/publishing_adv.asp
BioMedcentral 